\title{
PERFORMANCE EVALUATION OF DENSE BITUMINOUS MACADAM MIX - A REFUSAL DENSITY APPROACH
}

\author{
Nitinprasad.R ${ }^{1}$, M.S.Nagakumar ${ }^{2}$ \\ ${ }^{I}$ M. Tech IV semester, Highway Technology, ${ }^{2}$ Associate Professor, Department of Civil Engineering, R. V. College of \\ Engineering, Bangalore-560059, India \\ Lion_prasad@hotmail.com,nagakumar@rvce.edu.in,msnagakumar@gmail.com.
}

\begin{abstract}
Secondary compaction is a state; where the pavement which is compacted with the conventional compaction has been further compacted due to the movement of traffic and which corresponds to the ultimate density which can be attained on the bituminous pavement called as "Refusal density" of the pavement. Secondary compaction has to be studied in detail and it is understood that the 75 blows of the Marshall test does not determine the actual field circumstances. The Marshall design actually in the field will not simulate the field conditions hence there will be a reduction in the air voids at the refusal density. Then due to fineness of the mix, this causes the plastic deformation on the pavement surfaces. Hence an attempt has been made to study the air void content at refusal density. Also the Bulk Density, Air voids (Va), Voids in mineral aggregate (VMA),Voids filled with Bitumen (VFB) of the mix at the refusal density are also studied. For the simulation of the field density in the laboratory a Hugo hammer is used. The usage of the Polymer Modified Bitumen reduces the plastic deformation and other distresses of the pavement.
\end{abstract}

Keywords: Dense bituminous macadam (DBM), Refusal density, Hugo hammers.

- ***

\section{INTRODUCTION}

The important highways in India are built by Dense Bituminous Macadam (DBM) or Bituminous Concrete (BC). In India Marshall Method is adopted for designing bituminous mixes where specimens [1, 2, and 15] are prepared using Marshall Hammer. Compaction effort generated by Marshall Hammer does not simulate the field compaction effect which leads to aggregate degradation. The secondary compaction of the pavements has been neglected during the design of the mixes for the pavement. Secondary compaction is caused soon after the pavement is laid and the vehicles are allowed to move on them. Compaction plays a vital role in performance of a bituminous mixes. The drawback of Marshall Procedure is the number of blows given to compact the specimen is fixed. The conventional compaction effort by Marshall Method which is 75 blows is not adequate to examine the field condition in laboratory; hence the compaction energy in the laboratory has to be increased to the maximum called as the 'refusal density' of the pavements. To achieve the field densities and compaction efforts an improvised Marshall rammer called as Hugo hammer, having indentations on the surface can be made use. This type of compactor can simulate upto $90 \%$ of the field characteristics.

\subsection{Objectives}

1. To determine the optimum bitumen content of Dense Bituminous Macadam grading II (DBM II) Mix prepared using Polymer Modified Bitumen (PMB) and by Hugo hammer

2. To study behaviour of DBM mix at the refusal density with mix air voids under the conditions of secondary compaction.

3. To assess the Marshall Properties of DBM Mix prepared using PMB at optimum bitumen content by varying number of compaction blows.

4. To compare the Marshall properties of the specimen casted using Hugo hammer and the standard Marshall rammer at 75 Blows compaction effort.

\subsection{Need for Present Investigation}

1. In the areas where there are heavy movement of vehicles and also where the temperature of the pavement are really high the mix design done by the normal Marshall method is not appropriate so a new method of mix design has to be considered.

2. The normal assumption done in the Marshall method is that the density achieved during the test represents the actual density on the field after the pavement is allowed to the traffic movement. The severity caused by the movement of the traffic will be underestimated in this case.

3. The importance of maintaining the sufficient air voids in the Dense Bituminous Macadam during mix design is to have a minimum of $3 \%$ of Air voids at the refusal density. The design procedure for this has 
to ensure that the mix should be designed as to maintain the minimum Air void level (3\%) at the stage of refusal density.

\section{LITERATURE REVIEW}

The standard of road networks in developing countries is increasing and new roads have been built with thick asphalt concrete bituminous concrete (BC) surfacing to accommodate increasing traffic volumes. There are situations when the use of $\mathrm{BC}$ designed by the Marshall method is very difficult, if not inappropriate, such situations include; Smith et.al [1]

a) Areas of high traffic stresses such as climbing lanes and junctions;

b) Where high pavement temperatures occur; and

c) Where design traffic loading significantly exceeds 1 million ESA (equivalent standard axles), which is the minimum value of the Asphalt Institute definition of heavy traffic.

A fundamental assumption in the Marshall procedure is that the density obtained during the test represents the ultimate density of the $\mathrm{BC}$ in the road pavement after years of secondary compaction under traffic.

This is very difficult to predict and, where loading conditions are severe, it is most likely that the commonly used 75 blow Marshall Compaction will underestimate the effect of secondary compaction.

When secondary compaction of the BC surfacing is underestimated, there is a high risk that structural instability may develop and result in plastic deformation. The importance of maintaining sufficient air voids in the mix (VIM) after trafficking was emphasised in the Desert Roads Manual which required that heavy duty DBM for use in hot arid areas should retain VIM of not less than $3 \%$ at refusal density.

\subsection{Refusal Density}

Smith et.al [1], suggests the modification to the Marshall Design procedure which we follow for the design of asphalt mixes, i.e. 'Refusal density' procedure which takes into the account for the actual field loading on the pavements.

Sridhar et.al [2], to the Dense Bituminous Macadam (DBM) as a binder course used for roads with more number of heavy commercial vehicles adequate compaction in the DBM is crucial to the performance of flexible pavements. . In the recent past, Marshall Method has been observed not to simulate the field conditions. Present study attempts to simulate the field compaction in the laboratory by using Hugo hammer for laboratory compaction of DBM mix.

Rao et.al [3], the importance of retaining sufficient voids in the mix after trafficking to prevent plastic deformation and discusses limitations associated with the Marshall Design procedure. In these situations the commonly used 75-blow Marshall Compaction method underestimates the effect of secondary compaction under traffic and many of these surfacing suffer structural instability leading to severe plastic deformation.

\section{EXPERIMENTAL INVESTIGATIONS - BITUMINOUS MIX DESIGN}

The mix design selected for the present study is dense bituminous macadam - gradingII (DBMII). The mix design job mix formula was done according to the Asphalt Institute manual 2 (Manual series 2). According to that the aggregate selected are of ranges of proportions from $40 \mathrm{~mm}, 20 \mathrm{~mm}$, $12 \mathrm{~mm}$ and $6 \mathrm{~mm}$ as 2, 22.6, 42.4 and $33 \%$ respectively for Marshall Specimen preparation.

Table 1 Properties of the aggregate

\begin{tabular}{|l|l|l|}
\hline Properties & Values obtained & Specifications \\
\hline Impact value(AIV) in \% & $19.62 \%$ & $30 \%$ (MAX) \\
\hline Crushing value in \% & 22.84 & $45 \%$ (MAX) \\
\hline Flakiness \& Elongation index & 24.30 & $30 \%$ (MAX) \\
\hline Water absorption & 0.6 & 2 (MAX) \\
\hline $\begin{array}{l}\text { Abrasion value } \\
\text { (LOS ANGELES) }\end{array}$ & 17.34 & $30 \%($ MAX) \\
\hline
\end{tabular}




\section{LABORATORY INVESTIGATION}

\subsection{Aggregate}

The aggregates used in the present study were tested and found to meet MoRTH (Ministry of Road Transport and Highways) Specifications (2004). Coarse aggregate, fine aggregate and hydrated lime was used in the DBM II mix. The properties of aggregates are given in Table 1

\subsection{Specific Gravity of the Materials used in the} Present Study

Table 2 Specific gravity of the materials

\begin{tabular}{|l|l|}
\hline Description of materials & Specific gravity. \\
\hline Coarse aggregate & 2.83 \\
\hline Fine aggregate & 2.7 \\
\hline Filler (Lime) & 2.65 \\
\hline Polymer Modified Bitumen PMB-70(SBS) & 1.03 \\
\hline
\end{tabular}

\subsection{Binder}

For the laboratory study binder modified with SBS (PMB 70)

were considered in the present investigation. The physical properties of binders are given in Table 3 .

Table 3 Binder Properties

\begin{tabular}{|c|c|c|c|}
\hline Designations & Values obtained (PMB 70) & $\begin{array}{l}\text { Requirements } \\
\text { (PMB 70) }\end{array}$ & Method of Test. \\
\hline $\begin{array}{l}\text { Penetration at } 25^{\circ} \pm 0.1^{\circ} \mathrm{C}, 5 \\
\sec \end{array}$ & 56.2 & $50-70$ & IS : 1203-1978 \\
\hline $\begin{array}{l}\text { Softening Point, }(\mathrm{R} \& \mathrm{~B}) \\
{ }^{\circ} \mathrm{C},(\text { Glycerol }) .\end{array}$ & 82.45 & 55 (Minimum) & IS : 1205-1978 \\
\hline Ductility at $27^{\circ} \mathrm{C}, \mathrm{cm}$ & 89 & +60 (Minimum) & IS : 1208-1978 \\
\hline Flash point,${ }^{\circ} \mathrm{C}$, & 295 & 220 (Minimum) & IS : 1209-1978 \\
\hline Elastic recovery at $15^{\circ} \mathrm{C}$ & 83 & 75 (Minimum) & SP-53-2002 (Appendix-1) \\
\hline $\begin{array}{l}\text { Viscosity at } 150^{\circ} \mathrm{C}, \text { Brook } \\
\text { Field viscometer, Spindle No. } \\
27 \text {, at } 100 \text { RPM \& } 31.3 \% \\
\text { Torque, Poise }\end{array}$ & 6.45 & $2-6$ & ASTM - D- 4402 \\
\hline $\begin{array}{l}\text { Separation, difference in } \\
\text { softening point, } R \& B,{ }^{\circ} \mathrm{C} .\end{array}$ & 1.5 (T-82,B- 83.45) & 3 (Maximum) & $\begin{array}{l}\text { SP-53-2002 } \\
\text { (Appendix-2) }\end{array}$ \\
\hline
\end{tabular}




\section{STUDIES ON MARSHALL PROPERTIES OF BITUMINOUS MIXES}

The purpose of the Marshall test is to determine the optimum binder content for a particular blend of aggregates and bitumen.. The stability, flow, bulk densities, air voids and VFB are plotted versus bitumen content. The specimens used for the determination of Marshall Properties were casted using
Hugo hammer. Hugo hammer shall have the diameter of 100 $\mathrm{mm}, 3.2 \mathrm{~mm}$ Indents at every $30^{\circ}$. After every 10 blows the mould or the hammer face is rotated by an angle by $30^{\circ}$. Table 4 gives the Marshall properties of the PMB mix at OBC. Figure 2 to Figure 7 shows the Marshall properties of the materials for various compaction efforts in combined form. $\mathrm{OBC}$ is determined by weighted average technique and from Table OBC was found to ' 4.35 ',

Table 4 Marshall Properties of the DBM II at OBC

\begin{tabular}{|c|c|c|c|c|c|c|c|}
\hline Properties & $\mathbf{5 0}$ Blows & $\mathbf{7 5}$ blows & $\mathbf{1 0 0}$ blows & $\mathbf{1 5 0}$ blows & $\mathbf{2 0 0}$ blows & $\mathbf{7 5}$ Blows con & $\begin{array}{c}\mathbf{6 0 0} \\
\text { blows }\end{array}$ \\
\hline Bulk density, gram/cc & 2.286 & 2.359 & 2.35 & 2.375 & 2.372 & 2.354 & 2.427 \\
\hline Air voids, \% & 7.176 & 4.1214 & 4.63 & 3.43 & 3.76 & 5.12 & 1.497 \\
\hline VMA, \% & 19.78 & 16.41 & 17.25 & 16.48 & 16.5 & 17.78 & 14.522 \\
\hline VFB, \% & 63.73 & 75.54 & 73.2 & 77.58 & 77.47 & 71.27 & 89.816 \\
\hline Marshall stability. Kgs & 1445 & 1821.2 & 2127.5 & 2144.25 & 1926.33 & 1414.36 & 3418.5 \\
\hline Marshall flow, mm & 4.96 & 4.85 & 4.9 & 3.52 & 4.125 & 3.92 & 3.7 \\
\hline
\end{tabular}

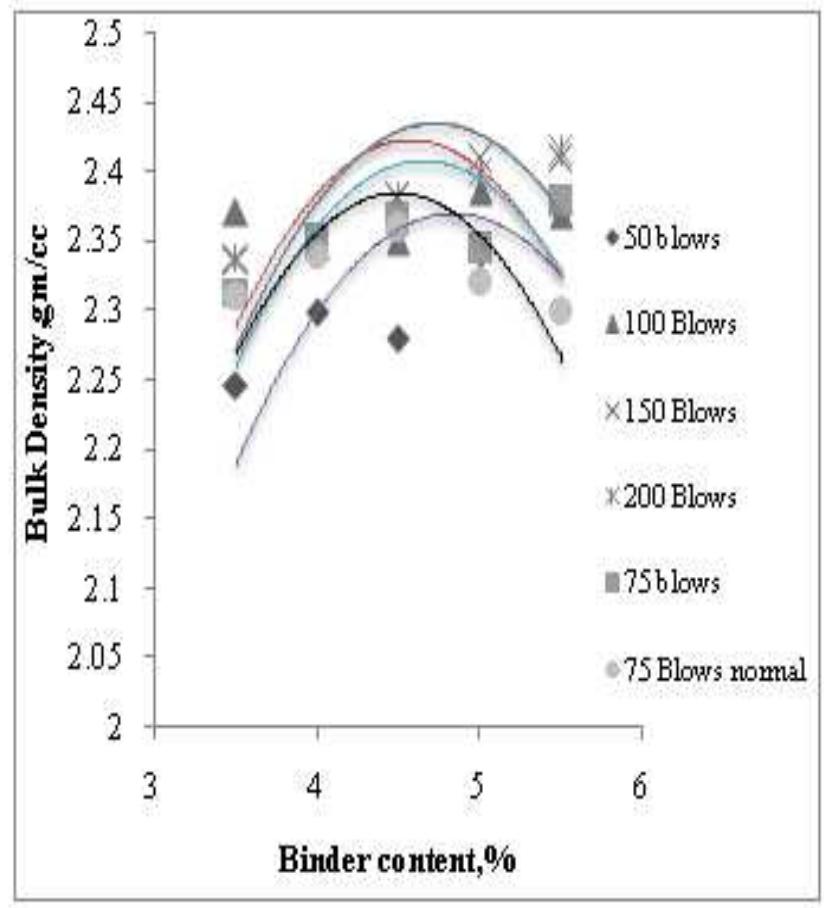

Fig1 Bulk Density Vs Binder content

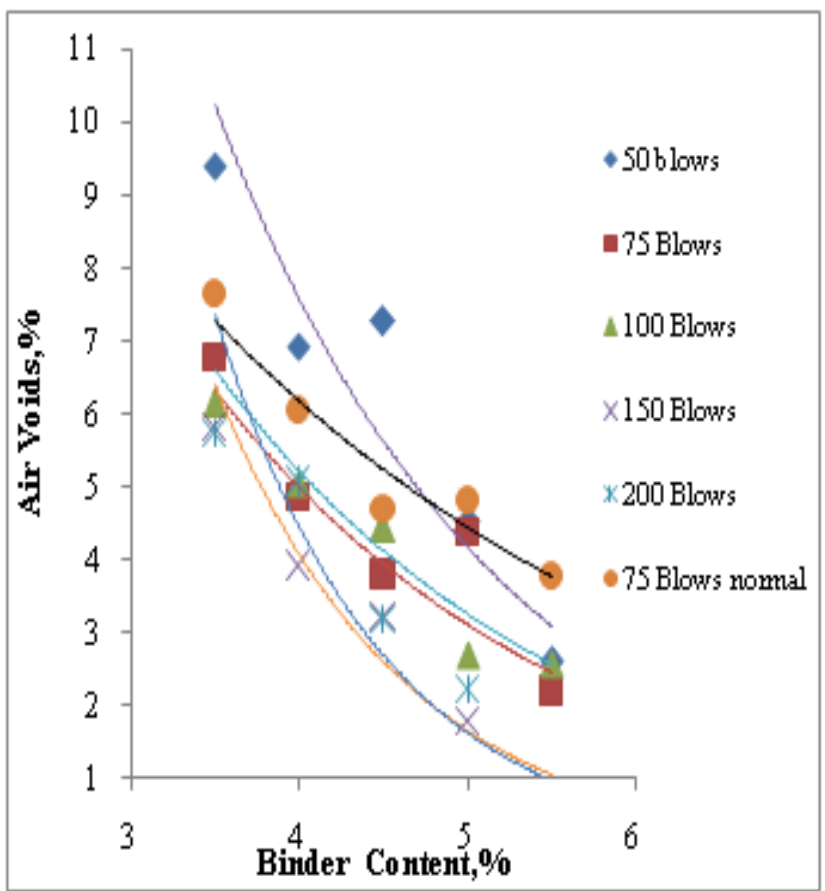

Fig2 Air voids Vs Binder content 


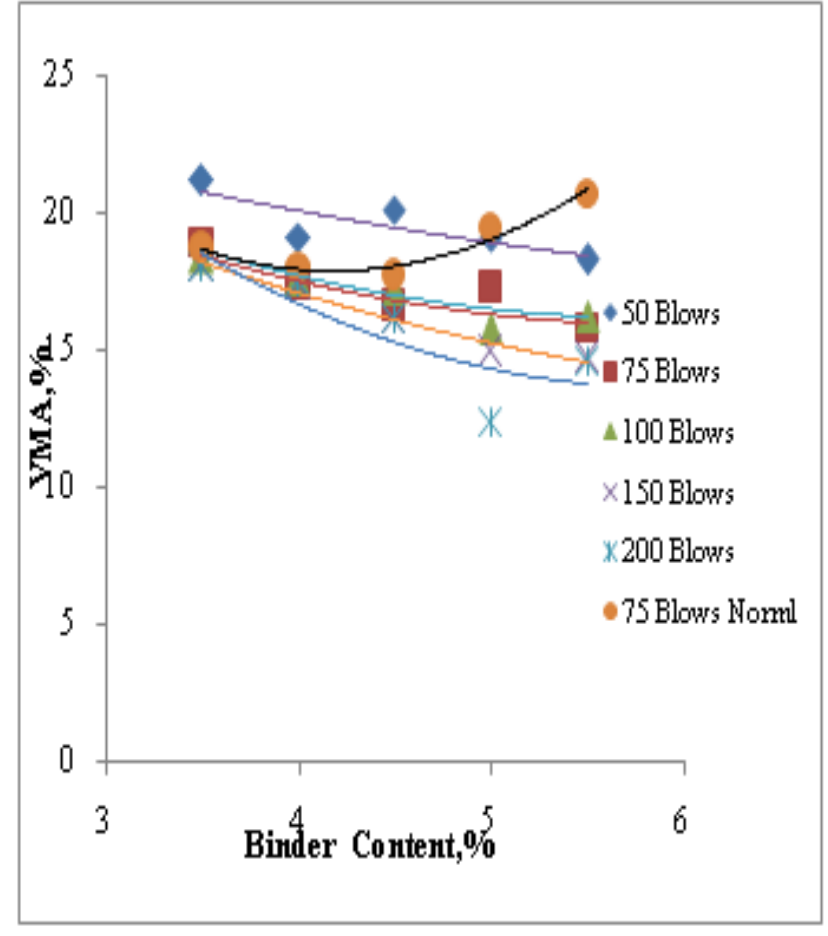

Fig3 VMA Vs Binder content

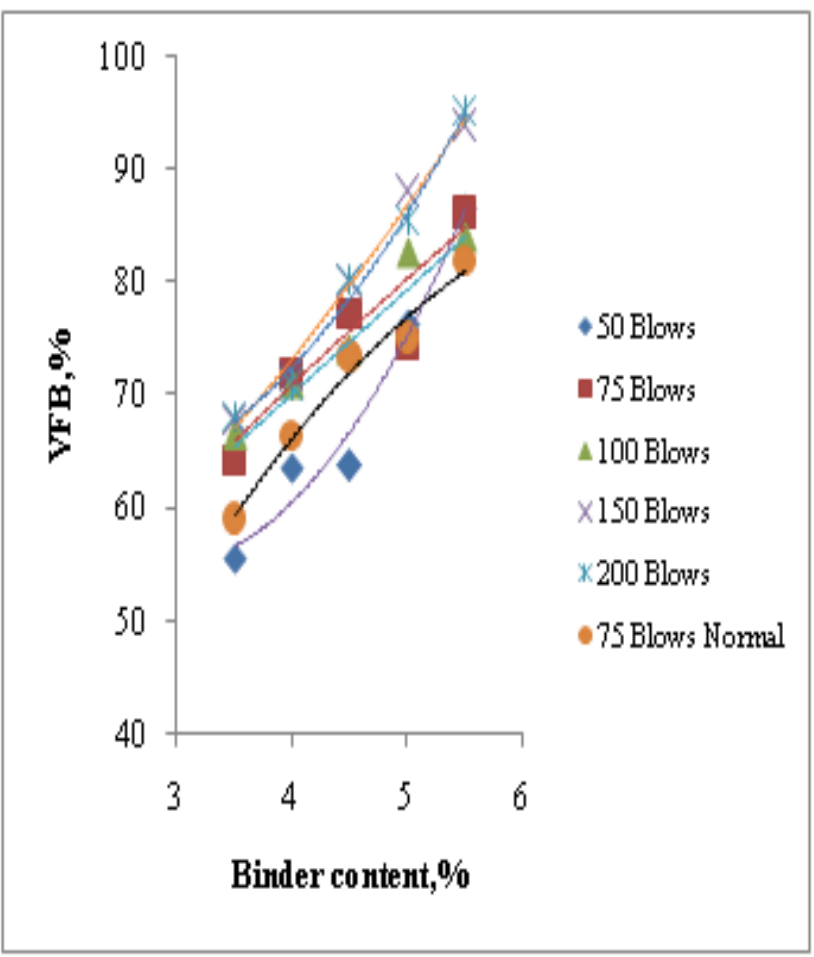

Fig4 VFB Vs Binder content

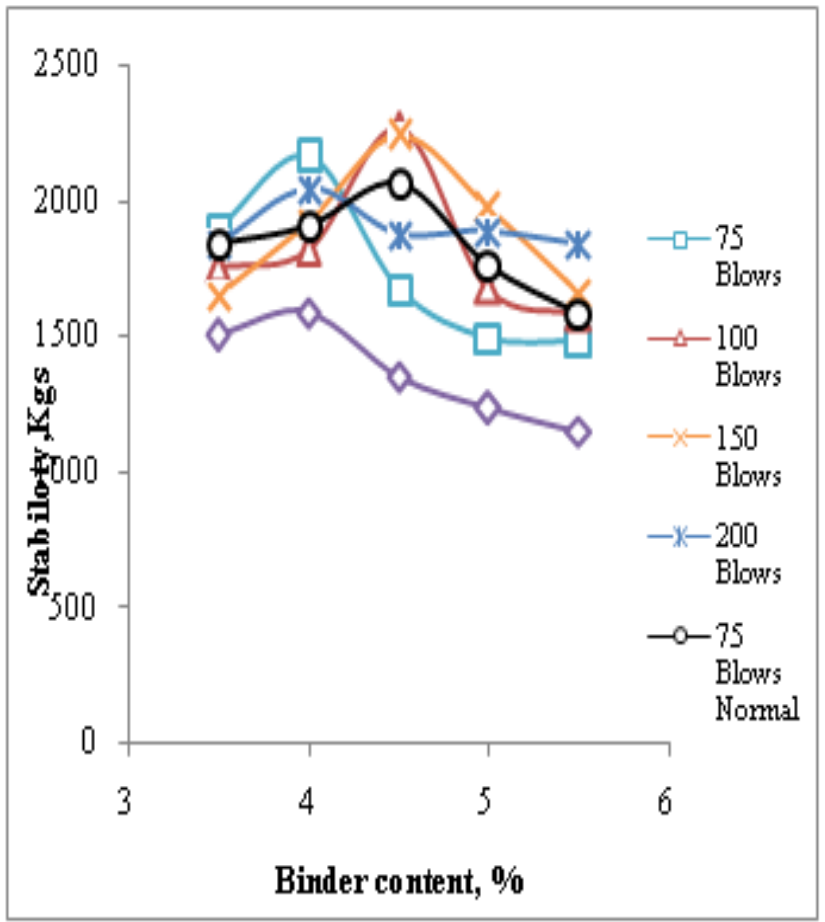

Fig5 Stability Vs Binder content

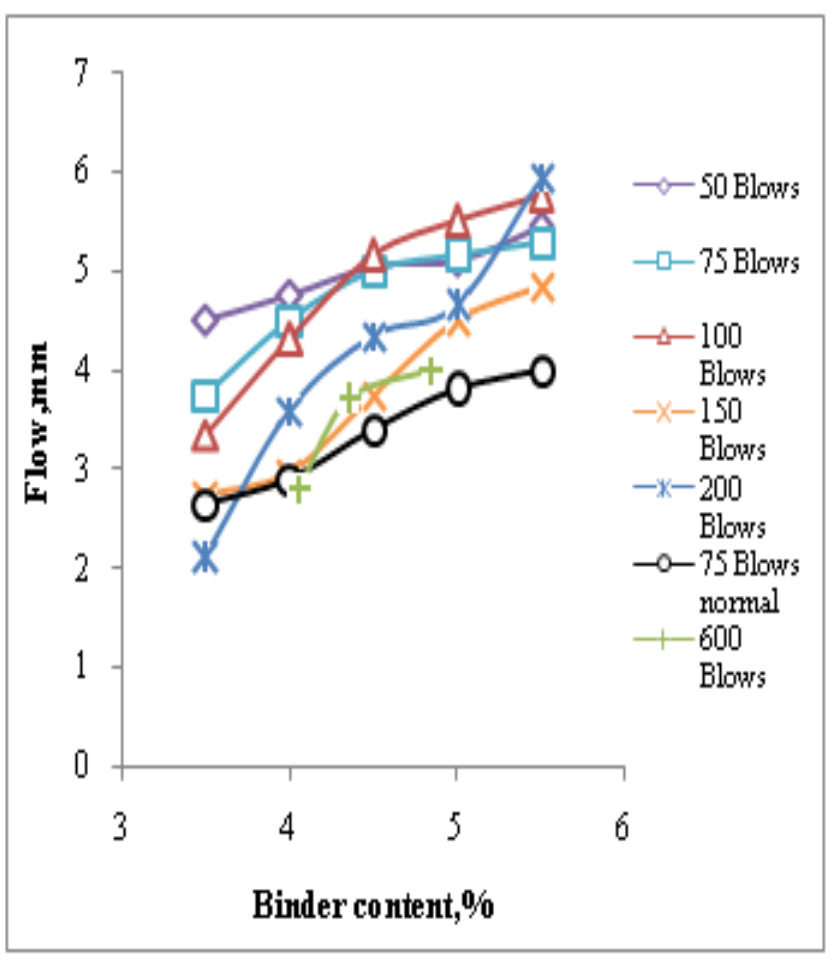

Fig6 Flow Vs Binder content 


\section{RESULTS AND CONCLUSIONS}

The experimental investigation has proved that the increase in the compaction energy shows a increase in the bulk density and decrease in the air voids level. 200 blows is obtained as the refusal density. At refusal density the air voids $\mathrm{Va}$ is $3.76 \%$ and the VMA is $16.5 \%$ also the stability is $1926.33 \mathrm{Kgs}$ at $\mathrm{OBC}$. For various blows the Marshall properties at $\mathrm{OBC}$ for 50 blows $\mathrm{Va}$ is 7.176 , VMA is 19.78 and Stability is $1445 \mathrm{kgs}$. 75 blows $\mathrm{Va}$ is $4.2 \%$, VMA 16.41 and stability $1812.2 \mathrm{kgs} .100$ Blows, Va is 4.63, VMA 17.25 and Stability is $2127.5 \mathrm{Kgs} .150$ Blows, Va is 3.43, VMA 16.48and Stability 2144.25. The 600 blows of compaction were done to evaluate the $\min \mathrm{Va} \%$ at maximum secondary Compaction. From analysing the results, the following can be concluded:

1. The variation in the Marshall properties plotted with binder content shows a different trend line for Hugo hammer compaction as compared to the normal Marshall rammer compaction

2. The bitumen content at the maximum bulk density is lesser than that for specimen compacted using Marshall Rammer

3. The stability of the mix prepared with Hugo hammer has increased when compared to that of the Conventional Marshall rammer.

4. The binder content of the specimen casted by Hugo hammer has lower values when compared to that of the Conventional Marshall rammer.

\section{REFERENCES}

[1] H.R.Smith and C.R.Jones, “ Bituminous Surfacing For Heavily Trafficked Roads In Tropical Climate", TRL Journal, Page 28 to 33, Feb 1998

[2] R.sridhar, C Kamaraj, Sunil Bose, P K Nanda and Manvinder Singh, “ Effects Of Gradation And Compactive Effort On The Properties Of Dense Bituminous Macadam Mixes", Journal of Scientific and Industrial Research, Page 56 to 59, January 2007

[3] Dr. S.K. Rao, J.K. Das \& Pinaki Roychowdhury, "Asphalt mix design - refusal density approach for heavily trafficked roads", Journal of the Indian Roads Congress, Page 53-64.2007

[4] S. S. Awanti, M. S. Amarnath and A. Veeraragavan, "Laboratory Evaluation of SBS modified Bituminous Paving Mix", Journal of materials in civil engineering ASCE, Page 327-330, April 2008.

[5] James Dwyer, Matt Betts, "Polymer-Modified Asphalt: Improving Our Nation's Infrastructure", University of Pittsburgh ,Swanson School of Engineering, Eleventh Annual Freshman Conference, April 9, 2011. 